\title{
Medios de comunicación alternativos para discapacitados visuales y auditivos. Análisis legislativo
}

\section{Alternative Means of Communication for the Visually and Hearing Impaired. Legislative Analysis}

\author{
Gretcher Lamas Bertrán * https://orcid.org/0000-0001-8068-8615 \\ Dayamis Ramírez Thomas ** https://orcid.org/0000-0001-6008-8508 \\ Mary Dennis Londres Osorio *** https://orcid.org/0000-0001-5679-5111 \\ http://dx.doi.org/10.21503/lex.v19i27.2264
}

* Licenciada en Derecho. Profesora Principal de Derecho Notarial y Derecho Internacional Privado en el Departamento de Derecho de la Universidad de Guantánamo, Cuba.

Correo electrónico: gretcherlb@cug.co.cu; gretcherlamas2@gmail.com

** Licenciada en Derecho. Profesora Principal de Derecho Civil General y Derecho Procesal Parte General en el Departamento de Derecho de la Universidad de Guantánamo, Cuba.

Correo electrónico: dayisrt@cug.co.cu

*** Licenciada en Derecho. Profesora Principal de Profesora de Derecho Internacional Público en el Departamento de Derecho de la Universidad de Guantánamo, Cuba. Vicepresidente del capítulo de Derecho Internacional Público en la Provincia de Guantánamo, Cuba.

Correo electrónico: maryd@cug.co.cu

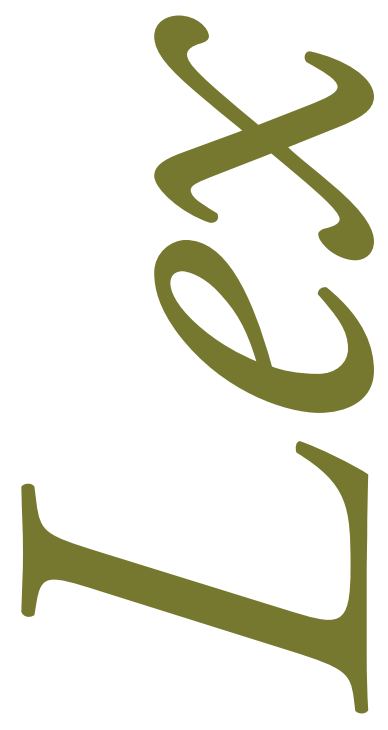




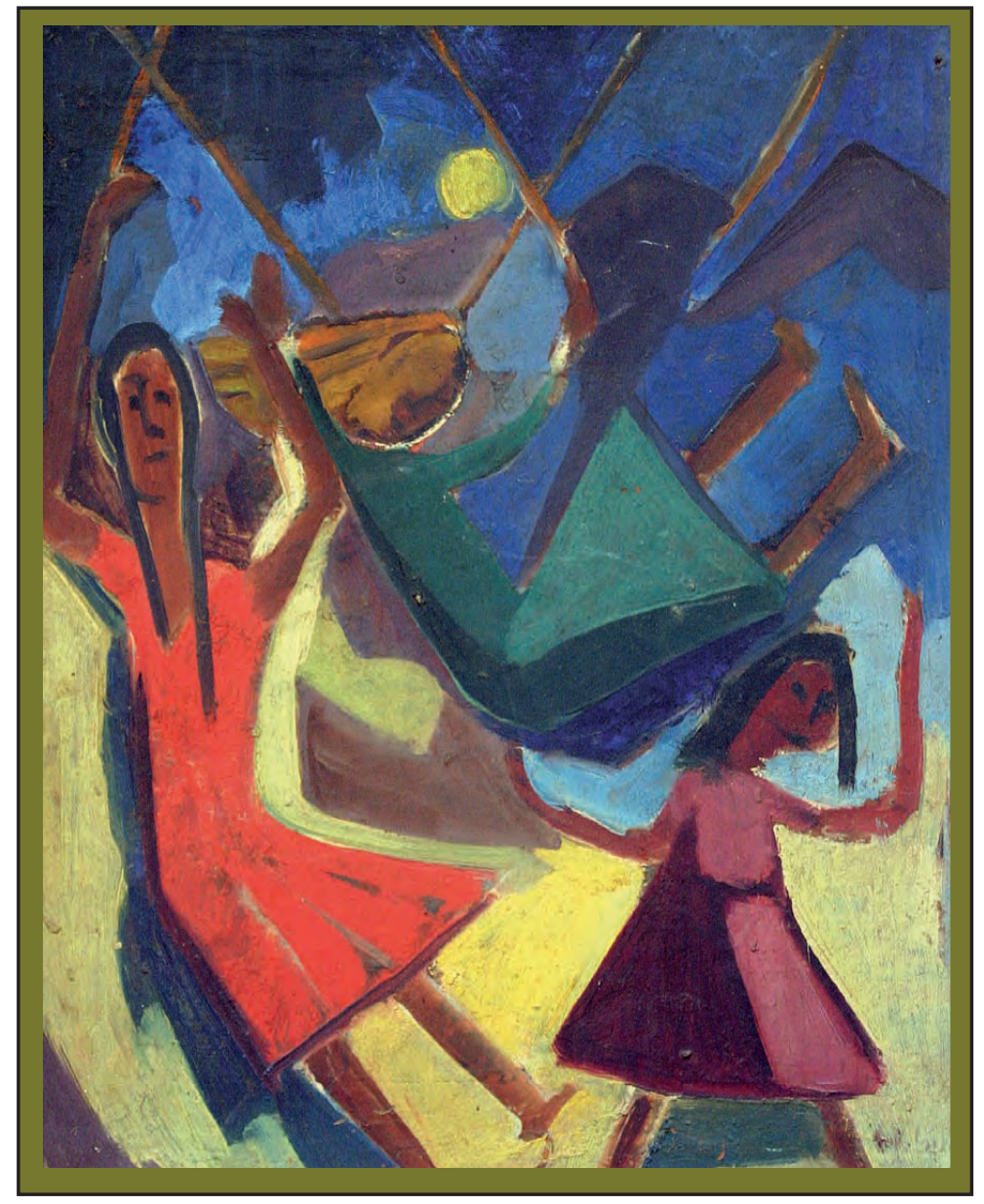

Los columpios. Carlota Carvallo pintora peruana del indigenismo (Lima 1909-1980). 


\section{RESUMEN}

En este artículo se pretende realizar un estudio en torno a los medios de comunicación alternativos como forma de lenguaje para las personas con discapacidad visual y auditiva, con un enfoque jurídico - constitucional, a partir de un análisis doctrinal y exegético que caracteriza el tratamiento jurídico dado a través del devenir histórico nacional, implementando propuestas de modificación al Código Civil cubano, así como la creación de una ley específica sobre discapacidad a fin de atemperar a la realidad la regulación legal de la figura que ahora se ilustra, tópico este escasamente tratado en la doctrina patria y foránea desde una dimensión jurídica. Para ello la presente investigación se ha auxiliado de diversos métodos generales tales como análisis-síntesis, inducción-deducción, y específicos de las investigaciones jurídicas entre los que pueden citarse el método teórico-jurídico y exegético-jurídico.

Palabras clave: Discapacidad-incapacidad-medios alternativos de comunicación.

\section{ABSTRACT}

I articulate in this it is intended to do a study about the alternative media like form of language for the people with visual and auditive disability, with a juridical focus - constitutional, as from an exegetic analysis that the juridical treatment given through the historic national vicissitude characterizes, implementing proposals of modification to the Constitution and to the Civil Code Cuban, in order to moderate the legal regulation of the figure that now we commented, topic this scarcely treated in the homeland doctrine and foreigner from a juridical dimension. For this, the present investigation has been aided by various general methods such as analysis-synthesis, induction-deduction, and specific ones of legal investigations, among which the theoretical-legal and exegetical-legal method can be mentioned.

Key words: Disability-incapacity-average alternative of communication. 


\section{INTRODUCCIÓN}

Si bien toda persona posee personalidad y goza de capacidad jurídica por el hecho de serlo, el ejercicio de esa capacidad va aparejado a ciertas condiciones que se expresan a través del modo de ser o estar el ser humano en el ámbito de la comunidad donde se desenvuelve, a su estado civil en sentido amplio. No siempre existe en el sujeto una plena madurez o aptitud para el ejercicio de la capacidad, pueden darse supuestos naturales o sociales que, sin despojar totalmente al individuo de la posibilidad de ejercitar sus derechos y concluir actos jurídicos eficaces, restrinjan su acción. Esta discapacidad natural, no afecta la capacidad jurídica per se, porque no niega la condición de persona del individuo afectado, que tiene personalidad y puede por ende ser sujeto capaz de contraer derechos y obligaciones.

El presente artículo, desde la perspectiva normativa abordada en la presente investigación, reviste sin duda gran importancia, ya que parte de reconocer la plenitud del goce de los derechos del discapacitado, tomando en cuenta que su ejercicio puede demandar requerimientos adicionales que debe propiciar la legislación, configurándose en este sentido los mecanismos propios de comunicación alternativa para el lenguaje en discapacitados visuales y auditivos, como expresión de respeto a su dignidad e igualdad social.

En nuestra academia patria, la concepción que se ha tenido sobre los discapacitados históricamente no ha sido congruente con su estado real. De manera general, se han rechazado sus deficiencias y como resultado no han integrado plenamente la sociedad, han sido apartado de ellas, marginados u ocultos. Sin tomar en cuenta el carácter de su ineptitud, muchas veces se les ha impedido la realización de una serie de actos que no siempre estuvieron en correspondencia con aquella. En base a lo anterior en el presente trabajo se hace un análisis de estos aspectos, pero vinculados ahora con los mecanismos de comunicación alternativos como forma de lenguaje, tópicos estos, no agotados en investigaciones anteriores.

De ahí que lo distintivo de esta investigación radique en realizar un estudio en torno a los medios de comunicación alternativos como forma de lenguaje para las personas con discapacidad visual y auditiva, con un enfoque jurídico - constitucional, a partir de un análisis exegético que caracteriza el tratamiento jurídico dado a través del devenir histórico nacional, implementando propuestas de modificación al Código Civil cubano, así como la creación de una ley específica sobre Discapacidad. 


\section{II- DISCAPACIDAD. ELEMENTOS NECESARIOS PARA UNA PRESENTACIÓN}

La discapacidad no constituye un fenómeno de reciente surgimiento en la historia de la humanidad, por el contrario, ha estado presente desde la aparición misma del hombre sobre la tierra, pues son los hombres quienes la padecen.

No cabe duda de que la definición de Discapacidad "es una cuestión que genera discrepancias, y que presenta variaciones según el modelo filosófico en el que se base, y según los contextos culturales dentro de las cuales se la defina" ${ }^{1}$. Como resalta Mike OLIVER, "el mundo social difiere del natural al menos en un aspecto fundamental: el ser humano asigna significado a los objetos en el mundo social y orienta su comportamiento hacia dichos objetos en los términos del significado que le ha asignado"2.

En lo que afecta a la discapacidad, si la misma es vista como una tragedia, entonces las personas con discapacidad son tratadas como si fueran víctimas de algo trágico. Dicho tratamiento no solo se manifiesta en las interacciones cotidianas, sino que también se traslada a las políticas sociales, a través de las cuales se intenta compensar a aquellas víctimas por las desventuras que padecen. Por el contrario, si la discapacidad es definida como un problema social, las personas con discapacidad son vistas como un colectivo, víctimas de una sociedad discapacitante, más que víctimas individuales de las circunstancias. De este modo, dicha visión es trasladada a las políticas sociales, tendentes a calmar las barreras sociales, más que a compensar a las personas de manera individual.

La Real Academia Española define a la discapacidad como "cualidad del discapacitado", y discapacitado como persona "que tiene impedida o entorpecida alguna de las actividades cotidianas consideradas normales, por alteración de sus funciones intelectuales o físicas”3. El diccionario de uso del español de María MOLINER señala que el prefijo dis transforma la idea de la palabra a la que se une en su opuesto: su sentido es peyorativo ya que proviene del griego dys que significa mal, trastornado ${ }^{4}$. En este Diccionario la Discapacidad aparece emparentada con Minusvalía a la que define como detrimento o disminución del valor que sufre una cosa.

En el año 1980 la Organización Mundial de la Salud, en su Clasificación Internacional de Deficiencias, Discapacidades y Minusvalías, en sus siglas “CIDDM", definió y distinguió entre tres conceptos: deficiencia, discapacidad y minusvalía ${ }^{5}$.

1. Francisco Bariffi y Agustina Palacios, La discapacidad como una cuestión de derechos humanos. Una aproximación a la Convención Internacional sobre los Derechos de las Personas con Discapacidad (Madrid: Grupo Editorial CINCA S.A, 2007), 57.

2. B. Ingstad, y Susan Reynolds White, Disability and Culture, (University of California Press, UnitedStates of America, 1995). En esta obra los autores indagan en el modo en que el concepto de discapacidad puede ser considerado una construcción cultural, por tanto, relativa y que varía según los contextos históricos, sociales y culturales.

3. RAE; Diccionario de la Lengua Española, 20 edición, tomo I, (México: Espasa Calpe, 2001), 831.

4. María Moliner; Diccionario de Uso del Español, tomo I, (Madrid: Gredos, 1997), 1010.

5. Vid. pág.1. 
Esta primera clasificación internacional provocó críticas considerables provenientes de organizaciones de personas con discapacidad, según afirman los autores Francisco Bariffi y Agustina Palacios ${ }^{6}$, por considerar que se mantenía cerca de las clasificaciones médicas, que relacionaban de manera ineludible y concadenada, la enfermedad con la discapacidad y la minusvalía. Ello debido a que se conserva la noción de deficiencia como anormalidad en una función, discapacidad como la incapacidad de realizar una actividad considerada normal para los seres humanos, y minusvalía como la incapacidad para desempeñar un rol social normal.

Como consecuencia de las críticas mencionadas, y siguiendo nuevos paradigmas respecto a la consideración de la discapacidad, la Organización Mundial de la Salud adoptó en el año 2001 una nueva Clasificación Internacional del Funcionamiento, la Discapacidad y la Salud (CIF)7. "La misma es una revisión de la anterior clasificación, su objetivo primordial es brindar un lenguaje unificado y estandarizado, y un marco conceptual para la descripción de la salud y los estados relacionados con la salud. En esta nueva clasificación, el término discapacidad engloba al de "deficiencia", "limitaciones en la actividad" y "restricciones en la participación" 8

Cabe destacar que desde la clasificación se persigue proporcionar un encuentro, desde una perspectiva múltiple, a la clasificación del funcionamiento y la discapacidad como un proceso participativo y evolutivo. Existe una interacción dinámica entre todos los elementos ya que las intervenciones en un elemento tienen el potencial de modificar uno o más de los otros. Así, por ejemplo, según el documento de la Organización Mundial de la Salud (OMS) una persona puede:

- Tener deficiencias sin tener limitaciones en la capacidad.

- Tener problemas de desempeño/realización sin deficiencias o limitaciones en la capacidad.

- Experimentar un grado de influencia en dirección contraria (así, la institucionalización puede provocar una pérdida de las habilidades sociales en muchas ocasiones).

Como puede apreciarse, a diferencia de la primera, la clasificación Internacional del Funcionamiento, la Discapacidad y la Salud se encuentra basada en la integración de dos perspectivas: la médica o biológica, y la social. Con el fin de conseguir la integración de las diferentes dimensiones del funcionamiento, la clasificación utiliza un enfoque "bio - psico - social" que intenta conseguir una síntesis, y, así, proporcionar una visión coherente de las diferentes dimensiones de la salud desde una perspectiva biológica, individual y social. Ello porque la clasificación parte de la idea de que ninguna de las dos

6. Francisco Bariffi, y Agustina Palacios, op.cit. , pp 59 - 60.

7. Organización Mundial de la Salud (OMS). Clasificación Internacional del Funcionamiento, de la Discapacidad y de la Salud. 54a Asamblea Mundial de la Salud, celebrada del 17 al 22 de mayo de 2001. (Madrid: IMSERSO,2001), acceso el 13 de marzo de 2017, http: //www.un.org/spanish/disabilities/oms.pd.

8. Francisco Bariffi y Agustina Palacios, op. cit., pp. 232 - 234. 
perspectivas (ni la biológica ni la social) resuelve por sí sola todas las cuestiones inherentes a esta realidad tan compleja que es la discapacidad.

A su vez, la Convención Interamericana para la eliminación de todas las formas de discriminación contra las personas con discapacidad en su articulado plantea que "la "discapacidad" significa una deficiencia física, mental o sensorial, ya sea de naturaleza permanente o temporal, que limita la capacidad de ejercer una o más actividades esenciales de la vida diaria, que puede ser causada o agravada por el entorno económico y social"'.

En lo que concierne a la Incapacidad, etimológicamente el vocablo está definido como "la falta de capacidad para hacer, recibir o aprender una cosa, rudeza, falta de entendimiento, carencia de aptitud legal para ajustar u obtener algo" ${ }^{10}$. María Moliner, lo define como "la cualidad o estado del incapaz, causa que incapacita en particular o legalmente"11.

\section{Conceptualmente se puede entender la incapacidad desde dos modelos:}

El modelo médico: considera la incapacidad como un problema personal directamente causado por una enfermedad, un trauma u otras condiciones de salud, que requiere de cuidados médicos prestados en forma de tratamiento individual por profesionales y encaminado a conseguir la cura o una mejor adaptación de la persona, así como un cambio en su conducta. Para lograrlo, la atención sanitaria se considera primordial.

El modelo social: entiende la incapacidad fundamentalmente como un problema de origen social, y principalmente como la ausencia de completa integración del individuo en la sociedad. La incapacidad no es un atributo de la persona, sino un complicado conjunto de condiciones, muchas de las cuales son creadas por el contexto y entorno social ${ }^{12}$.

Como puede apreciarse, el término, indistintamente puede referirse a la falta de capacidad para hacer, recibir o aprender algo; o de entendimiento o inteligencia; o la falta de preparación, o de medios para realizar un acto. Puede ser:

- Física: refiriéndose a la pérdida parcial o total de la capacidad innata de un individuo, ya sea por causas relacionadas con enfermedades congénitas o adquiridas, o por lesiones que determinan una merma en las capacidades de la persona, especialmente en lo referente a la anatomía y la función de un órgano, miembro o sentido.

9. Convención Interamericana para la eliminación de todas las formas de discriminación contra las personas con discapacidad, artículo 1, acceso el 22 de abril de 2018, http://www.oas.org/juridico/spanish/tratados/a-65.html.

10. Diccionario Ilustrado de la Lengua Española Aristos, (La Habana, Cuba: Editorial Científico Técnica, 1985), 353.

11. María Moliner, op.cit. 106.

12. M. J. Aguado Benedí, et al. Incapacidad y Discapacidad. Diferencias conceptuales y legislativas, acceso el 24 de abril de 2017, http: //www.aeemt.com/ 
- Jurídica: es la carencia de la aptitud para la realización del ejercicio de derechos o para adquirirlos por sí mismo.

- Mental: cuando se encuentra alterado el razonamiento, el comportamiento, la facultad de reconocer la realidad o de adaptarse a las condiciones de la vida.

- Incapacidad temporal o baja laboral, es la situación de un trabajador cuando por causa de una enfermedad común o profesional, o por un accidente está temporal o totalmente incapacitado para trabajar por indicación médica, y precisa asistencia sanitaria.

Atendiendo a lo expuesto con anterioridad, puede referirse que, desde el punto de vista semántico, resulta claro que capacidad y discapacidad aparecen como antónimos irreconciliables. En términos médicos, capacidad implica aptitud mientras que discapacidad implica lo contrario. La persona puede carecer de aptitud para el movimiento, para la comunicación, para atender su propio cuidado, pero esta ineptitud, proveniente de causas físicas, psíquicas o sensoriales, no le inhibe necesariamente el ejercicio de sus derechos ni la realización de todo tipo de actos jurídicos. De este modo, en materia jurídica, especialmente en sede civil, capacidad y discapacidad no siempre son contrarios, la ineptitud física o psíquica no llevaría de forma ineluctable a la incapacidad, puesto que esta solo procedería cuando se pruebe que aquella, priva a la persona de cabal juicio, de la posibilidad real de querer y entender, y de poder manifestar o expresar su voluntad de forma adecuada.

Capacidad - Discapacidad no son términos contrarios para el Derecho Civil obligadamente, y muchas veces la persona con discapacidades está apta para el ejercicio de sus derechos y la realización de actos jurídicos. Es preciso admitir que el problema de la integración de ésta a la vida socio - jurídica depende no solo de aspectos biológicos, sino que se trata de un tema dinámico que hay que analizar partiendo del contexto político, social y económico de cada Estado, y de los valores éticos y culturales de la comunidad. Discapacidad e incapacidad por lo general no son términos sinónimos. Al Derecho corresponde establecer las normas que permitan la adecuada distinción y proteger a las personas que padecen anomalías, ofreciendo vías para su completa incorporación a la sociedad y el libre desarrollo de su personalidad.

Para las autoras, discapacidad no es un defecto, sino una capacidad diferente que tiene la persona, lo que provoca limitaciones y restricciones en la realización de actividades de participación social. Jurídicamente la discapacidad no implica incapacidad, sin embargo, en numerosas ocasiones tachamos a los discapacitados como incapacitados restringiéndole su capacidad jurídica, siendo los discapacitados capaces de regir sus bienes y persona, muchas veces valiéndose de mecanismos alternativos que logren su plena inclusión en la sociedad, tal es el caso de los mecanismos alternativos de comunicación que fueron creados para este fin y que serán analizados a continuación. 


\section{DISCAPACIDAD VISUAL Y AUDITIVA Y LOS MECANISMOS ALTERNATIVOS DE LENGUAJE}

Desde un aspecto descriptivo se puede precisar que la discapacidad visual es la carencia, disminución o defecto de la visión. Para la mayoría de las personas, el significado de la palabra ciego, corresponde a una persona que no ve, con ausencia total de visión, sin embargo dentro de la discapacidad visual se pueden establecer otras categorías que también describen padecimientos concernientes a este grupo de personas ${ }^{13}$. La discapacidad visual es una condición que afecta directamente la percepción de imágenes en forma total o parcial; puede originarse por un inadecuado desarrollo de los órganos visuales o por padecimientos o accidentes que afecten los ojos, las vías visuales o el cerebro. Pueden surgir en diferentes edades y mostrar una evolución distinta, de acuerdo con la edad de aparición.

La sordera es la dificultad o imposibilidad de usar el sentido del oído debido a una pérdida de la capacidad auditiva parcial (hipoacusia) o total (cofosis), y unilateral o bilateral. Así pues, una persona sorda será incapaz o tendrá problemas para escuchar. Ésta puede ser un rasgo hereditario o puede ser consecuencia de una enfermedad, traumatismo, exposición a largo plazo al ruido, o medicamentos agresivos para el nervio auditivo ${ }^{14}$.

Los sistemas alternativos van dirigidos hacia aquellas personas que no tienen lenguaje oral y que es imposible que se dé a corto o largo plazo, o que se considera que el esfuerzo necesario para que el lenguaje se obtenga no es rentable y se necesita encontrar un sistema para que el sujeto se comunique. Los sistemas aumentativos por su parte, son aquellos que han sido diseñados para incrementar el habla: no suprime la verbalización ni el lenguaje oral, pero no es suficiente para establecer una comunicación satisfactoria, se utiliza principalmente con personas sordas.

Las personas que presentan este tipo de discapacidad presentan limitaciones en la capacidad sensorial ${ }^{15}$, por lo que pueden requerir de dispositivos de apoyo (bastones, programas informáticos de lectura de pantalla, audífonos u otros sistemas de amplificación de sonido), animales de asistencia (como perros guías), intérpretes o guías intérpretes, y/o información en formato accesible (Braille, lengua de

13. Ceguera Total o amaurosis: ausencia de respuesta visual. Ceguera Legal, $1 / 10$ de agudeza visual en el ojo de mayor visión, con correctivos y/o 20 grados de campo visual Disminución o limitación visual. Visión parcial: 3/10 de agudeza visual en el ojo de más visión, con corrección y/o 20 grados de campo visual total. Agudeza central reducida o la pérdida del campo visual: También se llama así a la baja visión, visión parcial o visión subnormal, y puede definirse como que, incluso con la mejor corrección óptica proporcionada por lentes convencionales, se traduce en una deficiencia visual desde el punto de vista de las capacidades visuales; supuesta en esta definición una pérdida bilateral de la visión, con algún resto visual. Categorías que podemos encontrar en el material Educación inclusiva: discapacidad visual, acceso el 13 de marzo de 2018, http://ecured.das.ccdp/index.php/Sistema Braille

14. Tipos de discapacidad auditiva, acceso el 13 de marzo de 2018,

https://colectivochuhcan.wordpress.com /2015/08/06/tipos-de-discapacidad-discapacidad-auditiva/

15. Vid. La discapacidad sensorial, acceso el 15 de marzo de 2018,

http://ecured.das.ccdp/index.php/discacidad_sensorial 
señas, comunicación táctil, entre otros). Las deficiencias sensoriales limitan la capacidad comunicativa e incluso, si son graves, pueden afectar a la percepción de la realidad, al aprendizaje del lenguaje y, como consecuencia de ello, a la organización del pensamiento.

El sistema de comunicación por excelencia en personas ciegas es el Braille que puede definirse como un sistema de lectoescritura táctil para ciegos. Consiste en un código convencional formado por combinaciones de puntos en relieve, agrupados en cédulas, que expresan letras, signos de puntuación, números y símbolos matemáticos y musicales. En el sistema Braille se emplean las mismas letras, números y signos de puntuación que cuando se escribe en tinta; la diferencia estriba en que se representan de forma distinta, a base de pequeños puntos en relieve ${ }^{16}$.

Las distintas combinaciones de estos puntos dan lugar a 63 combinaciones posibles y forman el alfabeto Braille. El tamaño real de la matriz ocupa el espacio de la yema de los dedos. La persona que lo utiliza pasa la yema de los dedos sobre la hoja impresa en Braille para identificar los distintos símbolos al tacto. En el sistema Braille la escritura es más rápida que la lectura y suele presentar menos dificultad. Un texto escrito en Braille se puede elaborar a mano o a máquina ${ }^{17}$. Se puede hablar de dos fase lectoras: la lectura unimanual y la lectura bimanual.

Las personas con discapacidad visual no suelen usar ningún sistema de acceso especial para trabajar con el ordenador. Utilizan en general el teclado ordinario, aunque no el ratón, excepto las personas con baja visión que sí pueden utilizarlo. Las salidas de información de un ordenador convencional son tres: a través de la pantalla, información impresa en tinta y salida auditiva. La auditiva, es la única que, sin un tratamiento previo, puede ser utilizada por las personas con déficit visual. En los otros dos casos es necesario realizar algunas adaptaciones. Los sistemas alternativos para adaptarlos son:

- Programas de ampliación: Algunos sistemas como Zoom-Text incorporan la salida auditiva del texto, mediante tarjeta de sonido, lo que ayuda al sujeto a situarse en la pantalla.

- Salida de voz: Las salidas de voz pueden ser de dos tipos, síntesis de voz o tarjetas de sonido.

- Salida en Braille: La línea Braille es un dispositivo que, conectado al ordenador, permite a la persona ciega la lectura de la información que muestra la pantalla del ordenador. Por medio de estos cursores, el usuario puede explorar toda la pantalla del ordenador.

16. Vid. Sistema Braille, acceso el 24 de marzo de 2018, http://ecured.das.ccdp/index.php/Sistema Braille.

17. Escritura a mano: Se puntea por detrás de la hoja y en sentido contrario al habitual, de derecha a izquierda, para que, al darle la vuelta a la hoja, la lectura se pueda realizar en sentido correcto, es decir de izquierda a derecha. Escritura a máquina: La máquina para la escritura Braille contiene seis teclas, una para cada uno de los puntos del cajetín generador Braille. Además tiene un espaciador, una tecla para el retroceso y otra para el cambio de línea. La más utilizada es la máquina Perkins. 
Las diferentes modalidades de comunicación con personas con deficiencia auditiva dependen de muchos factores: la edad a la que sobrevino el déficit, su severidad, las capacidades comunicativas y el entorno familiar y educativo. Los diferentes sistemas aumentativos y alternativos que se están utilizando para facilitar la comunicación de personas con deficiencias auditivas se pueden agrupar como métodos gestuales, oralistas y bimodales ${ }^{18}$.

El primer método mencionado se basa en que las funciones propias del lenguaje se realizan a través de signos, básicamente manuales y faciales, lo cual dificulta a veces la integración en la sociedad, debido a que no es un lenguaje conocido por todos; es el recurso natural para la comunicación entre las personas sordas ${ }^{19}$. Este lenguaje se basa en un sistema de comunicación visual, gestual y no oral, lo que justifica que se le considere un lenguaje alternativo a la lengua oral, aunque en algunos casos se pueda utilizar como sistema aumentativo para acceder a la lengua oral y escrita. La lengua de signos es el método gestual por naturaleza, sin embargo será necesario introducir previamente el alfabeto dactilológico, que le aporta algunos recursos útiles ${ }^{20}$.

El lenguaje de signos es un sistema simbólico signado manual, es decir, se realizan signos con movimientos de las manos y los brazos en el espacio. Para una mayor comprensión, los movimientos se acompañan de expresiones orofaciales que intensifican la comunicación. Este no es un lenguaje único: en cada país las lenguas de signos son diferentes, de la misma manera que lo son los lenguajes hablados, así se introduce el nombre del país correspondiente. Su finalidad es la misma que la del lenguaje oral: la comunicación, pero los procesos para conseguirla no son exactamente los mismos. Esto es debido a que la estructura del lenguaje de signos es diferente a la del lenguaje oral: tiene su propia gramática que nada tiene que ver con la de los lenguajes hablados.

En la lengua de signos la secuencia es simultánea, esto significa que el orden de los diferentes elementos deja de ser importante, ya que las acciones se representan en el espacio simultáneamente. Este hecho hace que la expresión de una frase compleja en el lenguaje de signos necesite aproximadamente el mismo tiempo que la misma frase expresada en lenguaje oral, tal como se puede apreciar en las traducciones simultáneas.

Por su parte, los métodos oralistas están basados en la palabra y en la lectura labial. En este sistema todo sonido debe ser leído en los labios, porque los complementos gestuales, por sí solos, no aportan información para descifrar ningún sonido. Es aplicable en edades tempranas, de modo que evita el vacío

18. Vid. Modelos comunicativos, acceso el 17 de marzo de 2018, http://ecured.das.ccdp/index.php/Modelos comunicativos

19. Vid. La lengua de signos, acceso el 17 de marzo de 2018, http://ecured.das.ccdp/index.php/Lenguaje_de_signos.

20. Alfabeto dactilológico: El alfabeto dactilológico consiste en reproducir las letras del alfabeto a través de signos hechos con las manos. De esta manera, la letra y el signo manual se corresponden: a cada letra le corresponde un signo concreto y a cada sigo le corresponde una letra. Es muy útil como complemento de la lengua de signos. Toda la comunidad sorda lo conoce y lo utiliza en determinadas situaciones, por ejemplo, para deletrear palabras extrañas. 
comunicativo de los primeros ańos y sirve para mejorar la lectura labial con menor esfuerzo. Se puede diferenciar entre método auditivo puro, la lectura labiofacial y la palabra complementada:

- Método auditivo puro: El método auditivo puro trabaja intensamente los restos auditivos, sin ayuda visual. Se aplica solo a las personas con sordera ligera o moderada. Es utilizado con personas que pueden desarrollar su vida sin ningún tipo de limitaciones, ya que su resto auditivo les permite un desenvolvimiento pleno.

- Lectura labiofacial: La lectura labiofacial es una técnica utilizada por las personas con dificultades auditivas mediante la cual captan la información de otra persona a través de la vista, interpretando la lectura de los labios y de la cara.

- La palabra completada (cued speech): La palabra completada es un sistema aumentativo de comunicación sin ayuda, que hace posible la percepción del habla a través de la vista. Suele ser insuficiente para una comprensión completa (los signos bucales visibles no permiten distinguir bien en algunos casos, ej. "caja" de "jaca"). Para subsanar este problema un buen recurso es el apoyo gestual complementario que aporta la palabra completada.

El método bimodal nace en un entorno predominantemente oralista con el objetivo de contribuir al desarrollo de la lengua oral. Se puede considerar el bimodal como un sistema aumentativo del habla que consiste en la producción de la lengua oral y su acompañamiento de signos para facilitar la visualización y la comprensión. Para ello utiliza signos simultáneamente al lenguaje hablado, siguiendo el orden, la estructura y las reglas sintácticas del lenguaje oral. Para su expresión gestual, el método bimodal utiliza signos y gestos de la lengua de signos. Se utiliza el lenguaje oral de la misma manera, en cambio la aportación gestual se reduce a signar las palabras que tienen contenido semántico (sustantivos, adjetivos, verbos y adverbios). Se utiliza especialmente para personas sordas, pero por su versatilidad puede extender su utilidad a personas con deficiencias graves para expresarse o afectadas por trastornos generales en su desarrollo. Existen diversos métodos bimodales, destacamos dos de ellos:

Sistema de signos Makaton, es un programa de lenguaje cuyo objetivo es proporcionar un medio de comunicación y fomentar el desarrollo del lenguaje en niños. Se aplica a personas con retraso mental, discapacidad o dificultades del lenguaje.

Programa de Comunicación Total, indicado para personas con graves trastornos de comunicación, autismo o trastornos profundos del desarrollo. En este programa las personas que se relacionan con el usuario sobre interpretan sus gestos intencionados, como si se tratara de demandas (de atención, de contacto, de acción, de objetos...), y le transmiten que son receptores motivados que atienden sus iniciativas de comunicación. 


\section{ACIERTOS Y DESACIERTOS EN NUESTRA LEGISLACIÓN}

En nuestro país, se regula a su vez desde la Constitución vigente, el derecho de asociación en su artículo $56^{21}$. A raíz de este articulado, todos los discapacitados cubanos tienen el derecho de afiliarse a una asociación correspondiente, según el tipo de discapacidad y siguiendo los Estatutos de la Asociación. En este sentido pudiéramos referirnos a la Asociación Nacional del Ciego (ANCI) ${ }^{22}$ y a la Asociación Nacional de Sordos de Cuba (ANSOC) ${ }^{23}$, estas se apoyan en las posibilidades que brinda el Estado Cubano para la ejecución de sus planes y programas, que guardan estrecha relación con el Plan de acción para la atención a las personas con discapacidad.

De lo referido con anterioridad, resalta el hecho de que el Estado Cubano desarrolla acciones que caracterizan y potencian la plena igualdad social entre los hombres. Desde los preceptos de nuestra Constitución, se definen y recogen los derechos y deberes de todos los ciudadanos para la plena participación en la sociedad y el derecho a la igualdad de oportunidades en consonancia incluso con normativas internacionales al respecto ${ }^{24}$.

Desde el propio articulado constitucional puede advertirse la ausencia en torno al régimen de atención y protección de las personas con discapacidad. El marco jurídico-institucional de protección dirigido a estas personas en Cuba se erige a partir de los mandatos reconocidos por el Título V, Capitulo II de la Constitución de la República, dedicado a los "Derechos". En este sentido, nuestra Ley Fundamental reconoce los derechos a la igualdad plena y a la no discriminación por razones de sexo, género, orientación sexual, identidad de género, edad, origen étnico, color de la piel, creencia religiosa, disca-

21. Artículo 56: Los derechos de reunión, manifestación y asociación, con fines lícitos y pacíficos, se reconocen por el Estado siempre que se ejerzan con respeto al orden público y el acatamiento a las preceptivas establecidas en la ley.

22. Fue fundada el 19 de julio de 1975 como una institución no gubernamental y no lucrativa de carácter nacional con personalidad jurídica y patrimonio propio. Esta organización tiene el propósito de agrupar a las personas con discapacidad visual (ciegos y con baja visión) en la promoción de acciones que contribuyan a su plena rehabilitación e integración social. Algunas de las acciones que constituyen líneas principales de trabajo de la asociación son la rehabilitación integral, el deporte, la recreación, la educación, la cultura artística literaria, el empleo, la atención particularizada a los niños, jóvenes y adultos mayores, entre otras. Estatutos de la Asociación Nacional de Ciegos de Cuba, 2005.

23. Es una organización social, no gubernamental, con personalidad jurídica y económica propia, de carácter nacional y permanente. Esta organización fue fundada el 3 de enero de 1978 y tiene como misión representar a la comunidad sorda e hipoacúsica de nuestro país con el fin de lograr su mayor integración a la sociedad y elevar la calidad de vida de esas personas. Para lograr lo anterior, la ANSOC se apoya en las posibilidades que brinda el estado Cubano para la ejecución de sus planes y programas, que guardan estrecha relación con el Plan de acción para la atención a las personas con discapacidad. Estatutos de la Asociación Nacional de Sordos de Cuba, 2008.

24. V.gr. Convención de los De $\neg$ rechos de las Personas con Discapacidad, de la cual nuestro país es signatario desde el año 2007. Dicho instrumento internacional propicia la toma de decisiones por las personas con discapacidad; incentiva un modelo en el que los ciudadanos, cualesquiera sean sus potencialidades, puedan decidir per se, de modo independiente y autónomo, o con un sistema de apoyos y salvaguardias reconocidas por el Derecho, sin que ello anule o les excluya de sus decisiones. 
pacidad y origen nacional o territorial ${ }^{25}$. Igualmente, el reconocimiento de los derechos a la seguridad social, la asistencia social, la atención de la salud y la educación, reconocidos en los artículos 68, 69, 70, 72 y 73 respectivamente, incluye a las personas con discapacidad ${ }^{26}$.

Además, y como un logro de la actual Constitución que no reflejaba la anterior, el artículo 89 se encuentra dirigido específicamente a la obligación del Estado, la sociedad y las familias para con los discapacitados al expresar: "El Estado, la sociedad y las familias tienen la obligación de proteger, promover y asegurar el pleno ejercicio de los derechos de las personas en situación de discapacidad. El Estado crea las condiciones requeridas para su rehabilitación o el mejoramiento de su calidad de vida, su autonomía personal, su inclusión y participación social”.

Sin embargo, en nuestro país aún no existe una ley específica referida a la protección de las personas con discapacidad que apoye y ayude a hacer realidad el precepto constitucional, aunque sí existen leyes como el Código de la Niñez y la Juventud, el Código de Familia, el Código Civil, el Código de Trabajo, el Código Penal y la Ley de Procedimiento Civil, Administrativo, Laboral y Económica, que regulan en ciertos aspectos el ejercicio de los derechos de estas personas.

El Código de la Niñez y la Juventud ${ }^{27}$ recoge en el artículo 30 que el Estado presta especial atención al desarrollo de las escuelas especializadas para niños con limitaciones físicas, mentales o con problemas de conducta, a fin de facilitarles, en la mayor medida posible y según sus aptitudes individuales, que además de valerse por sí mismos, se incorporen a la vida en sociedad.

Por otra parte el Código de Familia ${ }^{28}$ solamente se refiere a los derechos de los tutores o padres de personas incapacitadas que hayan sido declarados incapaces judicialmente. También expresa que serán sujetos de tutela los que hayan sido declarados incapacitados judicialmente por razón de enajenación mental y sordomudez u otra causa.

Nuestro Código de Trabajo ${ }^{29}$ en su artículo 2 expresa que todo ciudadano en condiciones de trabajar tiene derecho a obtener un empleo sin discriminación de color, sexo o discapacidad, también expresa en su Reglamento ${ }^{30}$ que las Direcciones de Trabajo pueden asignar un empleo a discapacitados y egresados de la Educación Especial. Exponiendo que según sus capacidades funcionales, habilidades adaptativas y preparación pueden emplearse según las posibilidades existentes en cada municipio y

25. Vid. Artículo 42 de la Constitución Constitución de la República de Cuba, (Editora Política, La Habana, 2019 ), 15. 26. Cfr. Artículos 68, 69, 70, 72 y 73, Constitución de la República de Cuba, 20-21.

27. Cfr. Ley No. 16 de 1978, Código de la Niñez y la Juventud, acceso el 5 de mayo de 2019, https://www.parlamentocubano.gob.cu/index.php/documento/codigo-de-la-ninez-y-la-juventud/.

28. Cfr. Artículo 138, Ley No. 1289/1975, Código de Familia, (Editora política, La Habana, 2010).

29. Cfr. Ley No. 116, Código de Trabajo, publicada en la Gaceta Oficial de la República de Cuba el 17 de junio de 2014. 30. Cfr. Decreto No. 326, Reglamento del Código de Trabajo, publicado en la Gaceta Oficial de la República de Cuba el 17 de junio de 2014. 
cuando sea necesario adecuar los puestos de trabajos o recibir un entrenamiento antes, siendo la entidad la encargada de realizar los mismos.

Mientras tanto el Código Penal ${ }^{31}$ en su artículo 20.1 expresa que está exento de responsabilidad penal el que comete el hecho delictivo en estado de enajenación mental, trastorno mental transitorio o desarrollo mental retardado, si por algunas de estas causas no posee la facultad de comprender el alcance de su acción o de dirigir su conducta. También expresa que el que abandone a un incapacitado o a una persona desvalida a causa de su enfermedad, de su edad o de cualquier otro motivo, siempre que esté legalmente obligado a mantenerlo o alimentarlo, incurre en sanción de privación de libertad de tres meses a un año o multa de cien a trescientas cuotas o ambas.

La Ley de Procedimiento Civil, Administrativo, Laboral y Económico a su vez, dentro de su articulado $^{32}$ regula que serán declarados judicialmente incapaces las personas por razón de enajenación mental y sordomudez. De la interpretación de este artículo se deriva que, en el caso de nuestro país, las personas con discapacidad auditiva específicamente sordomudos, son declarados por su discapacidad simplemente incapaces para ejercer por sí mismos actos jurídicos. Ello resulta incongruente con lo que establecen las Convenciones y normas internacionales que en los epígrafes anteriores fueron abordadas, pues el hecho de ser discapacitado, no necesariamente debe incluir una incapacidad, la que una vez declarada cercena todo ejercicio y capacidad jurídica en estas personas ${ }^{33}$.

El Código Civil ${ }^{34}$, como otra de las normas en la que la discapacidad encuentra regulación, no recoge expresamente el término discapacidad. Recientemente, fue dictada la Instrucción 244 de $2019^{35}$, que basándose en lo regulado en el artículo 30 apartado b) ${ }^{36}$ del referido cuerpo normativo, permite ejecutar un procedimiento para declarar la capacidad restringida hasta el momento no regulada, reflejando en el apartado noveno y vigésimo:

Noveno: El tribunal, para apreciar la causal de restricción prevista en el inciso b) del artículo 30 del Código Civil, frente a la indefinición respecto a la enfermedad o retraso mental que no implica una carencia total del discernimiento, tendrá que valerse de la experticia de especialistas en la materia, a fin de

31. Cfr. Artículo 20.1 de la Ley 62, Código Penal, de 29 de diciembre de 1987.

32. Cfr. Artículo 586 Ley 7, Ley de Procedimiento Civil, Administrativo, Laboral y Económico de 19 de agosto de 1977.

33. Cfr. Sentencia No. 669 de 30 de septiembre de 2004, Segundo Considerando. Ponente Acosta Ricart, Tribunal Supremo, Sala de lo Civil y de lo Administrativo.

34. Ley No. 59 de 16 de julio de1987, Código Civil (anotado y concordado), (La Habana: Editorial Universitaria Félix Varela, 2014).

35. Instrucción 244 de 2019, Gaceta Oficial de la República de Cuba, Edición Ordinaria, La Habana, 23 de abril de 2019, disponible en www.gaceta oficial.gob.cu.

36. Artículo 30: Tienen restringida su capacidad para realizar actos jurídicos, salvo para satisfacer sus necesidades normales de la vida diaria (...) b) los que padecen de enfermedad o retraso mental que no los priva totalmente de discernimiento. 
constatar la presencia en la persona de enfermedad física o psíquica, sea congénita o sobrevenida, que le produzcan un limitado autogobierno, que la enfermedad o deficiencia física o psíquica no genere en la persona que la padece un estado incapacitante permanente, y que las facultades cognoscitivas y volitivas de la persona no queden excluidas en toda su extensión, de modo que no se afecte completamente la potencialidad de entender o querer.

Vigésimo: Si no quedara acreditada la capacidad plena que se pretende modificar, sobre la convicción de que la enfermedad mental que invalidó el actuar consciente y voluntario de la persona no remitió del todo, se procederá a graduar su esfera de acción, acorde con las reglas que se instruyen, para declarar la restricción del ejercicio de la capacidad de obrar.

De manera general queda reflejado que en los diferentes cuerpos legales a los que se ha hecho alusión, aunque se recogen algunos derechos de los discapacitados, en ninguno se reconoce un concepto de discapacidad ni se hace referencia a la creación de alguna ley específica que regule su protección, refiriéndose solamente a discapacitados mentales y con limitaciones físicas, en esta última se entiende que se incluyen los discapacitados visuales y auditivos. Lo anterior representa una verdadera problemática, pues como bien plantea Migdalia Tamayo Téllez ${ }^{37}$, "el problema radica en que no se contempla y brinda protección desde la particularidad a cada tipo de discapacidad".

Tanto el Código de Familia, el Código Civil como la Ley Adjetiva, siguen una misma línea, pues sin atender a cada particularidad de la discapacidad que se trate, simplemente la norma parece resolver el conflicto restringiéndole en el mejor de los casos o declarándolos incapaces, aunque en el caso de los mecanismos de comunicación alternativos para el lenguaje, dado a la no regulación al menos en normas legales y por consiguiente su no reconocimiento, se limita el actuar de estas personas para realizar determinados actos jurídicos por sí mismos.

Sin embargo, aunque son notorios los avances en este sentido en nuestro país, básicamente en lo que refiere a la inclusión de los discapacitados en la sociedad, desde la arista jurídica persisten aún algunas insuficiencias en lo relativo a su regulación, pues en definitiva es el Derecho, el que debería desde su entramado normativo, brindarle la debida tutela judicial a fin de que no se vulneren sus derechos.

\section{UNA PROPUESTA DE CAMBIO EN CUBA}

En lo que concierne al reconocimiento legal de los mecanismos alternativos de comunicación para el lenguaje, regulados en la mayoría de las legislaciones foráneas consultadas, nuestras normativas resultan omisas al respecto, aún y cuando desde el plano social fomentamos la educación y la enseñanza de estos para las personas con discapacidad visual y auditiva.

37. Doctora en Ciencias Sociológicas, miembro de la ACLIFIM, Cuba. 
Este tipo de discapacidad en edades tempranas es analizado en el Centro de Diagnóstico y Orientación (CDO) para ubicarlos en centros de estudios atendiendo al tipo de discapacidad que presentan. Sin embargo, las autoras en visitas a este centro, han podido constatar la inexistencia desde el plano jurídico de este actuar, en este sentido solamente existen folletos ${ }^{38}$, que indistintamente recogen como parte de su contenido el actuar de los maestros con estas personas, el papel de la escuela, el uso de la informática, los medios de acceso importantes para nińos ciegos y con baja visión (Sistema Braille), conceptos de niños ciegos y con baja visión, concepto de pérdida auditiva y sordera, tendencias pedagógicas ${ }^{39}$ y componentes de la lengua de señas cubanas ${ }^{40}$. En estos propios folletos se aclara el reconocimiento oficial desde 1994 de la lengua de seńas como lengua natural y materna de las personas sordas y como alternativa pedagógica en el contexto escolar.

Las personas discapacitadas de la visión, oído y habla tienen formas de comunicación propias avaladas por organismos internacionales como el sistema Braille y los métodos oralista y gestual por lo que deberían regularse en alguna de nuestras leyes sustantivas como nuestro Código Civil, ya que la Constitución es omisa al respecto, hasta tanto no estén sentadas las bases para la creación de una Ley específica; hoy podríamos preguntarnos: ¿se le permite a un ciego otorgar testamento en sistema Braille? ¿Valdría la pena regular una nueva modalidad testamentaria para estos casos o insertar requisitos adicionales de validez? Según el pequeño Larousse escribir es figurar el pensamiento por medio de signos convencionales ¿acaso el Braille no lo es?

En lo que respecta a la comunidad sorda, se puede aseverar hoy que en nuestro país no existe aún una gramática de la Lengua de Señas Cubanas establecida, a partir de la cual definir su estructura y concebir de manera más eficiente su proceso de enseñanza-aprendizaje, incluso para el conocimiento de estas personas. Hay actualmente un poderoso movimiento en la opinión pública a favor del reconocimiento de las lenguas de señas como un idioma más, siendo regulado incluso en algunas Constituciones foráneas. En este sentido es válido acotar el hecho de que, en mucho de los casos, ha sido preocupación de nuestros intérpretes, la imposibilidad de reflejar mediante señas todo el entramado jurídico en determinados supuestos, V.gr los testamentos, en lo que a veces lo que esboza el fedatario público, se hace difícil de traducir por estos testigos idóneos.

De igual manera resultaría loable la creación de una ley específica sobre Discapacidad dada la reciente reforma constitucional acontecida en nuestro país, en la que pudiera incluirse entre otros aspectos medulares: los mecanismos de comunicación alternativos para el lenguaje, ello evitaría en muchos de

38. Cfr. El alumno con ceguera o con baja visión en la escuela regular. Un folleto de preparación para el maestro, (Cuba: Editorial Miriam Martínez, 2008); Actualidad en la educación de niños sordos, (Cuba Editorial Pueblo y Educación, 2003).

39. Para estas autoras dentro de este acápite vendrían a aparecer o a esbozarse los métodos de comunicación alternativos para lenguaje: Método oralista, gestual, bimodal y bilingüe.

40. Estos son: expresión facial, expresión corporal, señas o signos manuales, Alfabeto Manual Antiguo (AMA) o tradicional y alfabeto dáctil. 
los casos la declaración judicial de incapacidad que refiere la ley adjetiva para el caso de los sordomudos, pues certeramente pudieran intervenir en otros actos en los que su impedimento no afecte necesariamente su capacidad de obrar.

En el Código Civil, en lo que respecta a los incisos b y c del artículo 30, las circunstancias que caracteriza el legislador para considerar que debe limitarse o restringirse la capacidad de obrar de una persona, no están perfiladas con pulcritud, lo cual no resulta atinado en su expresión normativa, padeciendo el supuesto inexactitud en este sentido. De ahí la necesidad de continuar estableciendo normas de carácter tuitivo como la Instrucción antes mencionada, ante la carencia de ley específica al respecto, que coadyuven a la realización de sus derechos, a la consecución de una vida decente y tan plena como sea posible.

En el caso de los discapacitados sordomudos, aunque su afectación pueda dar lugar a un sinnúmero de situaciones, no todas impiden que estas personas puedan autogobernarse, pues su afectación no siempre le priva de conducirse con raciocinio, estas si bien pueden disminuir las condiciones de entendimiento y voluntad, no necesariamente deben anularlas. Bajo estos supuestos, bien pudiera valorarse quedar inmersos en la regulación del artículo 30 de la norma sustantiva y no incluirlos en los supuestos del precepto 32 del propio cuerpo legal que remite al artículo 586 de la ley adjetiva.

En este sentido, también es prudente aclarar que lo estipulado en el artículo 30 inciso c de nuestro Código Civil, resulta desacertado en cuanto a su redacción, toda vez que al expresar "los que por impedimento físico no puedan expresar su voluntad de modo inequívoco”, siendo la manifestación de voluntad el nervio central del negocio jurídico, bajo estos supuestos la persona debería declararse incapaz en congruencia con lo que declaran los artículos 67 y 68 de la referida norma, ya que todo negocio que carezca de una clara manifestación de voluntad es nulo y no puede convalidarse. Siendo así, pudiera pensarse en modificar la norma en el sentido de eliminar al sordomudo dentro de las causales de incapacidad, incluirlo en la modalidad de capacidad restringida prescindiendo de lo que refiere a manifestación de voluntad.

De un análisis en torno a la regulación legal de esta institución en nuestro país, consideramos prudente la creación en este sentido de una Ley específica en materia de Discapacidad, donde puedan ser contempladas estas personas a partir de un concepto propio de esta categoría, en la que puedan encontrar amparo atendiendo a sus especificidades, así como los mecanismos que posibiliten limitar su actuación en la esfera jurídica pero atendiendo realmente a la discapacidad que padezcan, pues cabe recordarse que la regla general es la presunción de capacidad plena.

\section{CONCLUSIONES}

El tratamiento a los discapacitados ha presentado una gran evolución, desde un trato peyorativo y discriminatorio hasta la inclusión dentro de la comunidad, al demostrarse con el paso del tiempo que la discapacidad no es causa de incapacidad sino una capacidad diferente que necesita de mecanismos 
especiales para que las personas discapacitadas alcancen la plena inclusión social; tal es el caso de los medios de comunicación alternativos para los discapacitados visuales y auditivos.

Aún y cuando desde el plano social nuestro país ocupe un lugar cimero respecto a la protección de las personas con discapacidad, desde la arista jurídica se advierten deficiencias en torno a la regulación legal de la misma, lo que a partir de la inexistencia de una ley especial que la regule, la declaración judicial de incapacidad a estas personas por el solo hecho de su discapacidad, denota discriminación hacia ellas; siendo necesario regular en una ley específica sobre discapacidad, la protección y derechos de las personas discapacitadas así como los mecanismos alternativos de comunicación para el lenguaje destinados a personas discapacitadas visuales y auditivas; la inclusión del sordomudo dentro de la modalidad de capacidad restringida y no de incapacidad dentro de la normativa civil.

\section{REFERENCIAS}

- Actualidad en la educación de niños sordos. Cuba: Editorial Pueblo y Educación, 2003.

- $\quad$ Aguado Benedí, M. J. et al. Incapacidad y Discapacidad. Diferencias conceptuales y legislativas. Acceso el 24 de abril de 2017 desde http: //www.aeemt.com/

- Bariffi, Francisco y Palacios, Agustina. La discapacidad como una cuestión de derechos humanos. Una aproximación a la Convención Internacional sobre los Derechos de las Personas con Discapacidad. Madrid: Grupo Editorial CINCA S.A, 2007.

- Convención sobre los derechos de las personas con discapacidad. Acceso el 13 de marzo de 2018 desde http://www.un.org/spanish/disabilities/.pdf

- Convención Interamericana para la eliminación de todas las formas de discriminación contra las personas con discapacidad, artículo 1 . Acceso el 22 de abril de 2018 desde http:/www.oas.org/juridico/spanish/tratados/a-65.html

- $\quad$ Constitución de la República de Cuba. Editora Política, La Habana, 2019.

- Diccionario Ilustrado de la Lengua Española Aristos. Habana, Cuba: Editorial Científico Técnica, 1985.

- Educación inclusiva: discapacidad visual. Ministerio de Educación, España. Acceso el 13 de marzo de 2018 desde http://ecured.das.Ccdp/index.php/SistemaBraille

- El alumno con ceguera o con baja visión en la escuela regular. Un folleto de preparación para el maestro. Habana Cuba: Editorial Miriam Martínez, 2008.

- $\quad$ Estatutos de la Asociación Nacional de Ciegos de Cuba, 2005.

- $\quad$ Estatutos de la Asociación Nacional de Sordos de Cuba, 2008. 
- Decreto No. 326, Reglamento del Código de Trabajo, publicado en la Gaceta Oficial de la República de Cuba el 17 de junio de 2014.

- Ingstad, B. Y Reynolds White, S. (eds.). Disability and Culture. United States of America, University of California Press: 1995.

https://www.ucpress.edu/book/9780520083622/disability-and-culture

- Instrucción 244 de 2019, Gaceta Oficial de la República de Cuba, Edición Ordinaria, La Habana, 23 de abril de 2019, Acceso el 4 de enero de 2021 desde www.gaceta oficial.gob.cu.

- La discapacidad sensorial. Acceso el 15 de marzo de 2018 desde http://ecured.das.ccdp/index.Php/ discapacidad sensorial.

- La lengua de signos. Acceso el 17 de marzo de 2018 desde http://ecured.das.ccdp/index.php/Lenguaje_de_signos

- Ley No. 1289/1975, Código de Familia, emitida por el Consejo de Ministros de la República de Cuba el 14 de febrero de 1975. Editora política, La Habana, 2010.

- $\quad$ Ley No. 116, Código de Trabajo, publicada en la Gaceta Oficial de la República de Cuba el 17 de junio de 2014

- $\quad$ Ley No. 7, Ley de Procedimiento Civil, Administrativo, Laboral y Económico, de 19 de agosto de 1977, modificada por el Decreto ley No.221/2006 de 26 de septiembre.

- $\quad$ Ley No. 16, Código de la Niñez y la Juventud, de 30 de junio de 1978. Acceso el 5 de mayo de 2019 desde https://www.parlamentocubano.gob.cu/index.php/documento/codigo-dela-ninez-y-la-juventud/

- $\quad$ Ley No. 59 de 16 de julio de 1987, Código Civil (anotado y concordado), Editorial Universitaria Félix Varela, La Habana, 2014.

- Ley 62 de 29 de diciembre de 1987, Código Penal (anotado y concordado), Editorial Félix Varela, la Habana, 2014.

- Modelos comunicativos. Acceso el 17 de marzo de 2018 desde http://ecured.das.ccdp/index.php/Modelos comunicativos

- Moliner, María. Diccionario de Uso del Español, tomo I. Madrid: Gredos, 1997.

- Organización Mundial de la Salud (OMS). Clasificación Internacional del Funcionamiento, de la Discapacidad y de la Salud. 54a Asamblea Mundial de la Salud, celebrada del 17 al 22 de mayo de 2001. IMSERSO, Madrid, 2001. Acceso el 13 de marzo de 2017 desde http: //www.un.org/spanish/disabilities/oms.pdf 
- RAE. Diccionario de la Lengua Española, 20 edición, tomo I. México: Espasa Calpe, 2001.

- Sentencia No. 669 de 30 de septiembre de 2004, Segundo Considerando. Ponente Acosta Ricart, Tribunal Supremo, Sala de lo Civil y de lo Administrativo.

- $\quad$ Sistema Braille. Acceso el 24 de marzo de 2018 desde http://ecured.das.ccdp/index.php/SistemaBraille

- Tipos de discapacidad auditiva. Acceso el 13 de marzo de 2018 desde https: //colectivochuhcan.wordpress.com/2015/08/06/tipos-de-discapacidad-auditiva/

RECIBIDO: 19/02/2021

APROBADO: 06/05/2021 


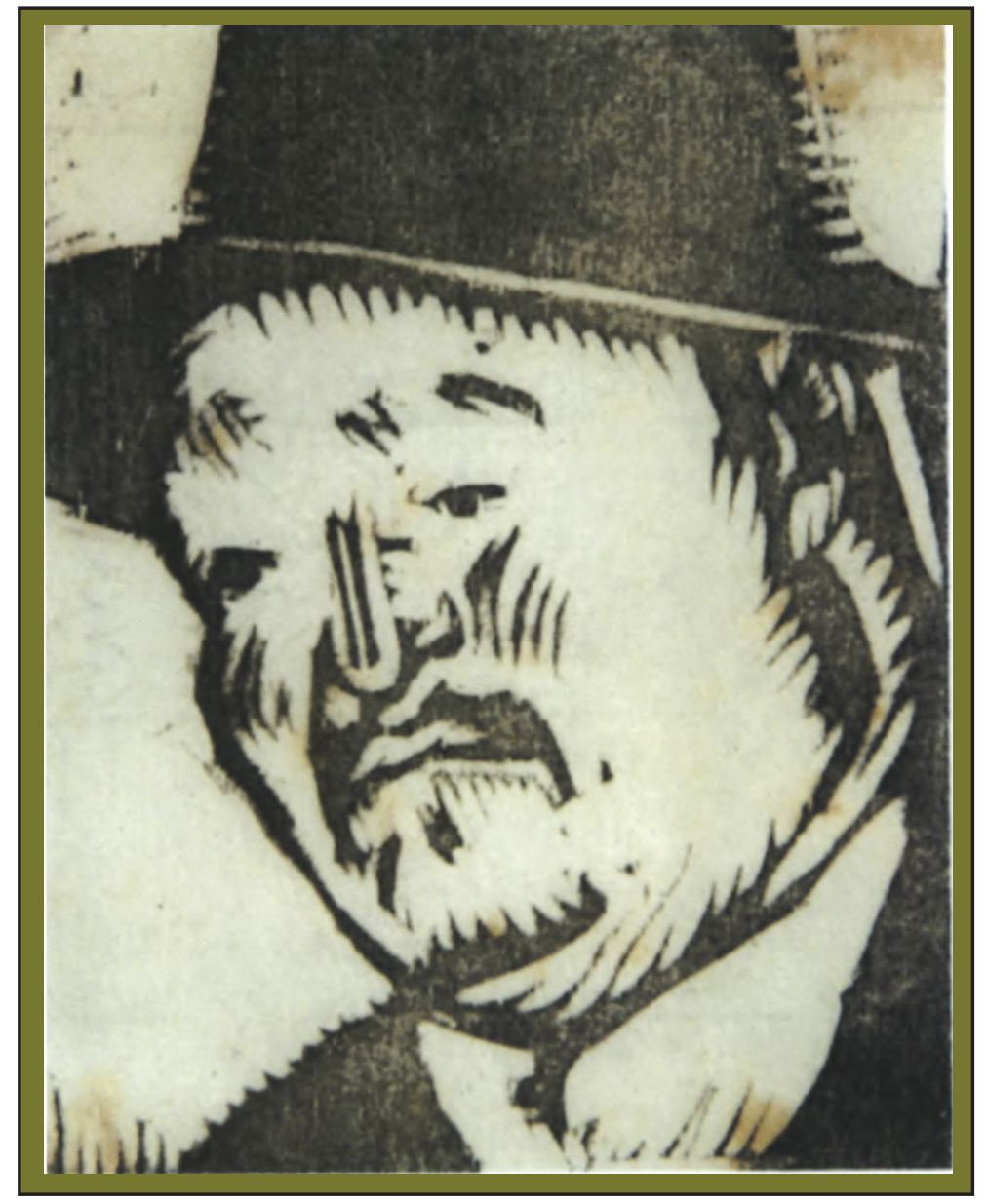

Cholo arequipeño. José Sabogal pintor peruano del indigenismo (Cajabamba-Cajamarca 1888-1957). 